\title{
The Influence of Alcohol Use Disorders on Sex and Mood in an HIV- infected Population in the State of Cear á, Northeastern Brazil
}

João Rafael Gomes de Luna', Wagner de Sousa Gurgel'1, Karla Julianne Negreiros de Matos², Emanuelle Meneses Barros ${ }^{1}$, Carolina Medeiros da Frota Ribeiro', Fábio Gomes de Matos e Souza ${ }^{3 *}$ and Affective Disorders Study Group

${ }^{1}$ Department of Clinical Medicine, Federal University of Ceará (UFC), Fortaleza, CE, Brazil

${ }^{2}$ Department of Psychology, Ceará State University (UECE), Fortaleza, CE, Brazil

${ }^{3}$ Department of Psychiatry, Department of Clinical Medicine, Federal University of Ceará (UFC), Fortaleza, CE, Brazil

\begin{abstract}
Background: This study assesses among 200 HIV-infected outpatients the prevalence of positive alcohol use disorder (AUD) and its correlations with socio-demographic characteristics, life habits, sexual behavior and (hypo) manic symptoms.

Methods: Between December 2009 and June 2011, patients were interviewed at the specialized clinic for HIVcare located in Walter Cantídio's University Hospital, Fortaleza, Ceará, Brazil. Screening for AUD was performed with the Alcohol Use Disorders Identification Test (AUDIT). A socio-demographic questionnaire based on WHO's Behavioral Surveillance Surveys was used to track risky sexual behaviors. The Mood Disorder Questionnaire (MDQ) was used to screen for symptoms of mania and hypomania.
\end{abstract}

Results: One hundred thirty-three patients (66.5\%) were male, mean age of 37.4 years (standard deviation, $S D=10.9)$ and mean years of study of $9.5(S D=3.5)$. Ninety nine patients $(49.5 \%)$ had AUD: $80(40 \%)$ had hazardous drinking and $19(9.5 \%)$ had alcohol dependence. AUD patients had higher rates of male gender $(\mathrm{OR}=2.8 ; 95 \% \mathrm{Cl}=1.5$, $5.2)$, living alone $(\mathrm{OR}=4.5 ; 95 \% \mathrm{Cl}=1.6,12.7)$, use of tobacco $(\mathrm{OR}=3.0 ; 95 \% \mathrm{Cl}=1.4,6.6)$, use of illicit drugs $(\mathrm{OR}=3.5$; $95 \% \mathrm{Cl}=1.7,7.1)$ and (hypo)manic symptoms $(\mathrm{OR}=6.4 ; 95 \% \mathrm{Cl}=2.3,17.7)$. Regarding sexual behavior, AUD was associated with lower age at first sex $(\mathrm{OR}=1.1 ; 95 \% \mathrm{Cl}=1.05,1.2)$ and higher prevalence of commercial $(\mathrm{OR}=2.7$; $95 \% \mathrm{Cl}=1.3,5.8)$ and non-regular sex partners $(\mathrm{OR}=4.3 ; 95 \% \mathrm{Cl}=2.1,8.6)$. In multivariate analysis, independent associations between AUD and the following variables were found: manic symptoms (adjusted Odds Ratio [aOR]=10.1; $95 \% \mathrm{Cl}=2.3,44.7)$, living alone $(\mathrm{aOR}=7.8 ; 95 \% \mathrm{Cl}=1.5,39.0)$, tobacco use $(\mathrm{aOR}=3.9 ; 95 \% \mathrm{Cl}=1.2,12.2)$, male gender $(\mathrm{aOR}=3.4 ; 95 \% \mathrm{Cl}=1.4,8.3)$, sex with non-regular partners $(\mathrm{aOR}=2.7 ; 95 \% \mathrm{Cl}=1.1,6.6)$, lower education $(\mathrm{aOR}=1.1$; $95 \% \mathrm{Cl}=1.03,1.2)$ and lower age $(\mathrm{aOR}=1.03 ; 95 \% \mathrm{Cl}=1.002,1.076)$.

Conclusion: Therefore, there is a significantly high prevalence of AUD among HIV-infected patients. AUD showed the following profile: young males, living alone, with lower education, higher rates of (hypo) manic symptoms and drug and sexual risk behaviors. A better understanding of AUD comorbidity and its implications on behavioral aspects of HIV-positive individuals may help in providing better long term outcomes of these patients.

Keywords: Alcohol use disorder; Sexual behavior; HIV/AIDS; Mood disorders

\section{Introduction}

The HIV epidemic remains a challenge for all public health systems around the world. It is estimated that 34.0 million people are now living with HIV/AIDS [1]. Several behavioral factors increase the risk of HIV infection, such as unprotected intercourse and injecting drug use (needle and syringe sharing) [2-4]. In Brazil, the prevalence of HIV infection is $0.6 \%$ among people aged between 15 and 49 years. Between 1980 and 2012, 2.1\% of the cumulative cases of HIV/AIDS in Brazil had been reported in the state of Ceará. The mortality due to HIV/AIDS showed a downward trend in the last decade in Brazil, reaching a level of 5.6 deaths per 100,000 inhabitants in 2011 [5].

Each year, approximately two and a half million deaths are caused by the harmful use of alcohol [6]. There is evidence available to support that alcohol use significantly increases the hazard of HIV transmission since it has been linked to impaired decision-making, which is associated with risky sexual behaviors [7-9]. Alcohol consumption has been reported to be associated with higher numbers of unprotected anal sex acts and condom failure $[9,10]$.

HIV-infected patients are also at increased risk of psychiatric disorders. Studies show high rates of substance use and mood disorders among patients with HIV infection, suggesting a substantial burden of mental disorders in this population $[11,12]$. Furthermore, substance use disorders and (hypo)manic symptoms may be risk factors for HIV transmission [13-15].

Manic and hypomanic episodes, which are the hallmark of bipolar disorder, may be characterized as a period of time where the patient has an elevated, expansive or irritable mood, and some typical symptoms are present, such as elevated self-esteem, disinhibition and hypersexuality. During these episodes, patients may also have higher rates of alcohol and illicit drugs abuse [16]. These symptoms and habits

*Corresponding author: Souza FGM, Associate Professor of Psychiatry, Department of Clinical Medicine, Federal University of Ceará (UFC), Fortaleza, CE Brazil, Tel: +55 853267 3867; Fax: +55 853267 3867; E-mail: fgmsouza@yahoo.com, br/getace@gmail.com

Received December 03, 2013; Accepted February 17, 2014; Published February 26, 2014

Citation: de Luna JRG, de Sousa Gurgel W, de Matos KJN, Barros EM, da Frota Ribeiro CM, et al. (2014) The Influence of Alcohol Use Disorders on Sex and Mood in an HIV-infected Population in the State of Ceará, Northeastern Brazil. J AIDS Clin Res 5: 285. doi:10.4172/2155-6113.1000285

Copyright: (c) 2014 de Luna JRG, et al. This is an open-access article distributed under the terms of the Creative Commons Attribution License, which permits unrestricted use, distribution, and reproduction in any medium, provided the original author and source are credited. 
may also increase the risk of HIV transmission since they are likely to interfere with safer sexual practices [17].

This paper aims to examine the prevalence of current alcohol use disorder (AUD) among HIV-infected outpatients attending a specialized unit of the Infectious Disease Department of Walter Cantídio's University Hospital in Fortaleza, Brazil, and also to assess sexual behavior and (hypo)manic symptoms in HIV patients who have AUD versus those who do not have AUD.

\section{Materials and Methods}

\section{Design and setting}

A cross-sectional study was conducted at one of the largest reference services for HIV-care in the state of Ceará, Brazil, which is located in the Walter Cantídio's University Hospital (HUWC), a teaching hospital of the Federal University of Ceará. The HUWC is a public general hospital with 247 beds. It has currently 170 medical residents.

The city of Fortaleza is located in Northeastern Brazil, three and a half degrees below the Equator. Fortaleza is the fifth largest city in Brazil, with a population of approximately 2.5 million and a gross domestic product (GDP) of around US\$ 18 billion [18].

\section{Sample}

Study participants were male and female patients meeting the inclusion criteria: HIV positive, 18 to 65 years of age, attending the HUWC and able to provide informed consent. There was no financial compensation for participation.

The study was performed on the two weekdays with a higher influx of patients to the clinic. All patients attending the clinic on those days between December 2009 and June 2011 were invited by the physician responsible for their HIV treatment to enroll for AUD, risky sexual behaviors and (hypo)manic symptoms screening. A total of 217 patients were invited, which represents $63 \%(\mathrm{~N}=344)$ of the total patients followed-up by the clinic. Five patients declined to participate and all 212 participants signed an informed consent.

\section{Instruments}

The socio-demographic and clinical questionnaire was used in order to assess the following aspects: gender, age, education, employment situation, marital status, living alone, use of tobacco, number of years since HIV diagnosis and use of illicit drugs. In Brazil, the following drugs are illicit: marijuana, cocaine, crack cocaine, heroin, among others. The results of the screening for (hypo)manic symptoms, as well as CD4 and viral copies count, were also recorded in this questionnaire. All instruments were interviewer administered.

The Alcohol Use Disorders Identification Test (AUDIT) is a screening instrument for AUD, including harmful or hazardous alcohol use and alcohol dependence [19]. It is a 10-item questionnaire which covers the domains of alcohol consumption, drinking behavior, and alcohol-related problems. Responses to each question are scored from 0 to 4 , giving a maximum possible score of 40 . A score of 8 or more is associated with harmful or hazardous drinking. A score of 13 or more in women, and 15 or more in men, is likely to indicate alcohol dependence. All patients who screened 8 or more were considered as having AUD.

The questionnaire of sexual behavior was based on WHO's Behavioral Surveillance Surveys (BSS) - Guidelines for Repeated Behavioral Surveys in Populations at Risk of HIV [20], which is a reliable method to track HIV risk behaviors. The following sexual behaviors were considered in accordance with the BSS questionnaire in this study: early sexual initiation measured by mean age at first sex; men who have sex with men; having regular partners; having commercial partners (i.e., a partner who has been given or received money, gifts, favors in exchange of sex); having non-regular partners (sex with partners irregularly, without a definition of a next date and that was not a commercial partner); and consistent condom use - which means using a condom every time a person has sex: with regular, non-regular and commercial partners. Patients were asked about having these behaviors in the lifetime. Other variables analyzed in this study, which are associated with sexual behavior, were sexual orientation, defined as reported by the patient such as heterosexual $(\mathrm{N}=124,57$ males, 67 females) and non-heterosexual (this category included patients who reported to be homosexual or bisexual; $\mathrm{N}=75,75$ males) and percentage of participants infected with HIV through sex.

The Mood Disorder Questionnaire (MDQ) is a self-report screening instrument for mood spectrum disorders, containing 13 yes/no items about (hypo)manic symptoms [21]. The MDQ starts with this question: "Has there ever been a period of time when you were not your usual self?" Additional items assessed for aspects such as, "you felt much more self-confident than usual; you got much less sleep than usual and found you didn't really miss it; you were much more interested in sex than usual; you did things that were unusual for you or that other people might have thought were excessive, foolish, or risky". The portuguese validation was done by our group [22]. Patients had a positive screening if they have answered "yes" to seven or more of the 13 items, as well as reported these symptoms to have occurred in the same period of time and caused moderate or serious psychosocial impairment [21].

\section{Data analysis}

Statistical analysis was performed using SPSS version 19.0 (SPSS Inc., Chicago IL). Comparison between AUD and non-AUD patients was done as follows: chi-square tests $\left(\chi^{2}\right)$ were used for categorical variables; continuous variables were assessed by Student's t-test.

The odds ratios (OR) and corresponding 95\% confidence interval (CI) were calculated in univariate analysis to assess how the fact of having AUD may be correlated with demographic characteristics, positive MDQ screening and sexual behaviors.

Multivariate analysis was conducted using binary logistic regression in order to determine adjusted odds ratios (aOR). The odds ratios were calculated by multivariate regression in which the dependent variable was AUD or non-AUD, and independent variables were demographic, clinical and sexual behavior features. Variables with $p<0.20$ in univariate analysis were included in the logistic regression model in order to assume that potential confounders were not excluded from the analysis. This cutoff for eligibility in the multivariate analysis has been also selected in previous studies with similar proceedings for data analysis [23-25]. Those with $\mathrm{p}<0.05$ were retained in the final multivariate logistic model in a backward stepwise manner, and were considered as independently associated with AUD. The Hosmer-Lemeshow test was employed for goodness of fit of the logistic regression model.

\section{Ethics}

The study protocol was approved by the Ethics Committee of the Federal University of Ceará.

\section{Results}

\section{Results of AUDIT screening}

From the initial 212 participants, a sample of 200 patients comprised 
the final study population. Twelve patients were excluded due to incomplete data. Eighty (40.0\%) patients had harmful or hazardous drinking and nineteen (9.5\%) had alcohol dependence. Therefore, 99 (49.5\%) patients had AUD.

\section{Demographic characteristics, clinical background and sexual behavior}

Table 1 shows demographic features, clinical background and sexual behavior characteristics of the sample. AUD patients when compared to non-AUD patients showed significantly higher percentages of the following variables: male gender, living alone, use of tobacco, use of illicit drugs, positive screening through MDQ, lower age at first sex, higher rates of sex with commercial and non-regular partners in lifetime. No significant differences were found in all other variables between these two groups (AUD vs. non-AUD).

\section{Multivariate analysis}

The following variables were considered eligible $(\mathrm{p}<0.20)$ for the multivariate analysis: male gender; age; years of study; divorced or widower; living alone; use of tobacco; use of illicit drugs, years since HIV diagnosis; positive MDQ screening; age at first sex; condom use during first sex; sexual orientation; HIV infection through sex; consistent condom use with regular partner; and having sex with commercial and non-regular partners.

Table 2 shows the result of multivariate analysis carried out through the binary logistic regression model. Positive MDQ screening, male gender, living alone, fewer years of study, use of tobacco, sex with nonregular partners and lower age were independently associated with AUD in this study. The Chi-square goodness of fit in the HosmerLemeshow test was not significant in any of the 8 steps of binary logistic regression, with a value of $8.7(\mathrm{p}=0.36)$ in step 1 , and a value of 6.5 $(\mathrm{p}=0.59)$ in step 8 .

\section{Discussion}

In this study, almost half of the HIV-positive patients had alcohol use disorder (49.5\%). It is higher than the rates of AUD estimated in the Brazilian general population $[26,27]$. The rate found in this study is 6 times higher than the one found by Mendonza-Sassi and Beria (7.5\%),

\begin{tabular}{|c|c|c|c|c|c|}
\hline Demographics & AUD (N=99) & Non-AUD (N=101) & Statistical test & $p$-value & OR $(95 \% \mathrm{Cl})$ \\
\hline Male; n (\%) & $77(77.8)$ & $56(55.4)$ & $x^{2}=11.192$ & 0.001 & $2.8(1.5-5.2)$ \\
\hline Age; mean (SD) & $36.3(11.1)$ & $38.6(10.6)$ & $t=-1.50, d f=198$ & 0.13 & \\
\hline Years of study; mean (SD) & $9.1(3.5)$ & $9.9(3.6)$ & $t=-1.70, d f=194$ & 0.09 & \\
\hline \multicolumn{6}{|l|}{ Employment situation } \\
\hline Employed; n (\%) & $54(55.1)$ & $50(49.5)$ & $X^{2}=0.625$ & 0.42 & $1.2(0,7-2,1)$ \\
\hline Unemployed; n (\%) & $27(27.6)$ & $33(32.7)$ & $x^{2}=0.620$ & 0.43 & $0.7(0.4-1.4)$ \\
\hline Retired; n (\%) & $13(13.3)$ & $14(13.9)$ & $x^{2}=0.015$ & 0.90 & $0.9(0.4-2.1)$ \\
\hline \multicolumn{6}{|l|}{ Marital status } \\
\hline Single; n (\%) & $50(50.5)$ & $45(44.6)$ & $x^{2}=0.710$ & 0.39 & $1.2(0.7-2.2)$ \\
\hline Married; n (\%) & $41(41.4)$ & $41(40.6)$ & $x^{2}=0.014$ & 0.90 & $1.0(0.5-1.8)$ \\
\hline Divorced or widower; $\mathrm{n}(\%)$ & $8(8.1)$ & $15(14.9)$ & $X^{2}=2.252$ & 0.13 & $0.5(0.2-1.2)$ \\
\hline Living alone; n (\%) & $19(19.2)$ & $5(5.0)$ & $x^{2}=9.602$ & 0.002 & $4.5(1.6-12.7)$ \\
\hline Use of tobacco; n (\%) & $27(27.3)$ & $11(10.9)$ & $X^{2}=8.718$ & 0.003 & $3.0(1.4-6.6)$ \\
\hline Illicit drug use; n (\%) & $36(36.4)$ & $14(13.9)$ & $x^{2}=13.501$ & $<0.001$ & $3.5(1.7-7.1)$ \\
\hline \multicolumn{6}{|l|}{ Clinical background } \\
\hline Years since HIV diagnosis; mean (SD) & $4.0(3.1)$ & $4.8(4.2)$ & $t=-1.45, d f=198$ & 0.14 & \\
\hline CD4 count; mean (SD) & $501.1(304.9)$ & $515.1(246.0)$ & $t=-0.32, d f=158$ & 0.74 & \\
\hline Viral copies count; mean (SD) & $10762.3(35861.1)$ & $15380.2(53639.6)$ & $t=-0.62, d f=156$ & 0.53 & \\
\hline Positive MDQ screening; $\mathrm{n}(\%)$ & $25(25.3)$ & $5(5.0)$ & $x^{2}=16.162$ & $<0.001$ & $6.4(2.3-17.7)$ \\
\hline \multicolumn{6}{|l|}{ Sexual behavior } \\
\hline Age at first sex; mean (SD) & $15.2(2.7)$ & $17.1(5.0)$ & $t=-3.26, d f=192$ & 0.001 & $1.1(1.05-1.2)^{*}$ \\
\hline Condom use during first sex; $\mathrm{n}(\%)$ & $16(16.8)$ & $26(26.0)$ & $x^{2}=2.418$ & 0.120 & $0.5(0.2-1.1)$ \\
\hline Sexual orientation & & & $x^{2}=3.829$ & 0.050 & \\
\hline Non-heterosexual; n (\%) & $44(44.4)$ & $31(31.0)$ & & & $1.7(0.9-3.1)$ \\
\hline Heterosexual; n (\%) & $55(55.6)$ & $69(69.0)$ & & & $0.5(0.3-1.0)$ \\
\hline HIV Infection through sex; n (\%) & $82(82.8)$ & $74(73.3)$ & $x^{2}=2.663$ & 0.103 & $1.7(0.8-3.4)$ \\
\hline Sex with regular partner; n (\%) & $95(96.0)$ & $96(95.0)$ & $x^{2}=0.096$ & 0.756 & $1.2(0.3-4.7)$ \\
\hline Consistent condom use ${ }^{2} ; \mathrm{n}(\%)$ & $2(2.1)$ & $6(6.3)$ & $X^{2}=2.044$ & 0.153 & $0.3(0.06-1.6)$ \\
\hline Sex with commercial partners; $\mathrm{n}(\%)$ & $27(27.3)$ & $12(11.9)$ & $x^{2}=7.545$ & 0.006 & $2.7(1.3-5.8)$ \\
\hline Consistent condom use; $\mathrm{n}(\%)^{3}$ & $9(33.3)$ & $6(54.5)$ & $x^{2}=1.472$ & 0.225 & $0.4(0.1-1.7)$ \\
\hline Sex with non-regular partners; $\mathrm{n}(\%)$ & $84(85.7)$ & $58(58.0)$ & $X^{2}=18.742$ & $<0.001$ & $4.3(2.1-8.6)$ \\
\hline Consistent condom use; $\mathrm{n}(\%)^{4}$ & $17(20.5)$ & $12(21.1)$ & $x^{2}=0.007$ & 0.935 & $0.9(0.4-2.2)$ \\
\hline
\end{tabular}

*For this variable, the OR and $95 \% \mathrm{Cl}$ were calculated through binary logistic regression.

Table 1: Demographic characteristics and clinical background. 


\begin{tabular}{|l|c|c|}
\hline Variable & OR $(95 \% \mathrm{Cl})$ & $p$ \\
\hline Positive MDQ screening & $10.1(2.3-44.7)$ & 0.002 \\
\hline Male & $3.4(1.4-8.3)$ & 0.007 \\
\hline Living alone & $7.8(1.5-39.0)$ & 0.012 \\
\hline Years of study & $1.1(1.03-1.2)$ & 0.013 \\
\hline Use of tobacco & $3.9(1.2-12.2)$ & 0.016 \\
\hline Sex with non-regular partners & $2.7(1.1-6.6)$ & 0.027 \\
\hline Age & $1.03(1.002-1.076)$ & 0.038 \\
\hline \multicolumn{2}{|r|}{ Table 2: Results of multivariate analysis. } \\
\hline
\end{tabular}

using the same instrument (AUDIT) in a population-based sample of 1,260 subjects [27]. This finding supports the association between HIVpositive serostatus and AUD, although our sample is not representative of the HIV infected population.

The comparison among studies in this field is somewhat difficult due to different definitions of what is meant by alcohol use disorder. In this sense, other HIV-infected population studies have used different measures instead of AUDIT. To exemplify these differences, it is worth mentioning a study with a random sample of 2,340 people living with HIV, which showed a prevalence of harmful drinking of $27 \%$ using the AUDIT-C, a 3-item modified version of AUDIT, and of $12 \%$ using the CAGE questionnaire [28].

The prevalence of AUD in our study was much higher than in other studies assessing HIV-infected outpatients $[28,29]$. A study conducted in the United States by Chander et al. with a sample of 951 HIV-positive patients from 14 HIV care sites showed $11 \%$ of hazardous alcohol use and $29 \%$ of moderate alcohol use, with moderate meaning any alcohol use at less than hazardous level [29]. In that study, hazardous alcohol use was defined according to US National Institute on Alcohol Abuse and Alcoholism (NIAAA) guidelines: $>14$ drinks per week (196 g of alcohol) or $\geq 5$ drinks (70 g) per any single occasion for men and $>7$ drinks (98 g) per week or $\geq 4$ drinks (56 g) per any single occasion for women. The different rates may be partially explained due to methodological dissimilarities. Besides instruments and sample sizes differences, that study comprised a broader geographic distribution.

In this sample, male gender was associated with AUD. The percentage of males among AUD patients was $77.8 \%$. This finding is consistent with results of other HIV-infected population studies [29,30]. Chander et al. has found association of male gender with any alcohol use, but not with hazardous alcohol use [29]. Bertholet et al. has found association between female gender and favorable drinking patterns, which is defined as "not drinking risky amounts at each assessment or decreased drinking over time" [30].

AUD patients showed almost a 4 times higher percentage of people who live alone. This fact may have severe implications, since living alone is associated with substantially increased risk of alcohol-related mortality [31].

Prevalence of tobacco use was 2.5 times higher among AUD than non-AUD patients. Also, patients with AUD showed a 2.6 times higher percentage of illicit drug use in lifetime than those non-AUD, which is consistent with other studies that showed association between current illicit drug use and hazardous alcohol use/heavy drinking among HIV-infected individuals $[29,32]$. These habits may represent a worse prognosis for this group given the reported associations of substance abuse and HIV disease progression [32-35].

AUD patients had, on average, sexual initiation almost two years earlier than those non-AUD, as well as higher prevalence of non- regular and commercial sex in lifetime. AUD may be associated with a higher probability to be exposed to other sexually transmitted diseases in this population, and other study also reported the same HIV risk behaviors correlated with alcohol use [36]. This association is a possible explanation for the increased risk of HIV-infection among alcohol users.

The non-heterosexual group, which has, in this study, the same meaning as men who have sex with men (MSM), since all who reported to be non-heterosexual are men, was more likely to have AUD. The confidence interval (0.997-3.184) was close to 1, which almost reached statistical significance. Stress related to social stigma is a possible explanation for the apparent heightened risk of AUD in this group [37]. A recent study reported that AUDs are prevalent among MSM and are associated with increased HIV risk-taking behaviors [38]. In this sense, interventions targeting problematic drinking may contribute to reduce risky behaviors associated with HIV transmission among MSM.

Positive MDQ screening in AUD patients was 25.3\%, 5 times higher than in non AUD-patients. It means that the rate of $15 \%$ of MDQ+ found in the whole sample (200 patients) is mainly due to AUD patients. Indeed, mood disorders, especially bipolar disorder, frequently are associated with substance use disorders [39]. This finding could be linked to the higher rates of risky sexual behaviors among AUD patients, since sexual impulsivity is a typical characteristic of manic/ hypomanic episodes.

Multivariate analysis showed that some of the variables discussed above, such as positive MDQ screening, male gender, living alone, use of tobacco and sex with non-regular partners, were independently associated with AUD in our study. It was also observed that fewer years of study and lower age, although not significantly associated with AUD in univariate analysis, remained in the final logistic regression model with $\mathrm{p}<0.05$.

Positive AUD screening was associated with lower mean number of years of study. A recent study has found an association between alcohol abuse/dependence and worse educational attainment even after controlling for genetic and environmental confounds [40]. However, it is not possible to know if these events were directly related in this study.

The finding of lower age among AUD patients is consistent with the epidemiologic situation of alcohol abuse/dependence in our country. Other studies conducted in Brazil showed a higher prevalence of binge drinking among adults of younger age brackets $[41,42]$. This result can be partially related to marketing strategies targeting younger adults by associating alcohol use to moments of leisure $[42,43]$.

This study has some limitations. Firstly, it was not possible for researchers to interview patients attending the clinic on all weekdays, so days with largest number of appointments, corresponding to two-thirds of the total number, were chosen. These appointments were randomly scheduled, therefore a selection bias of the population was not observed. Another limitation is that, while AUDIT assesses alcohol use in the last year, most of the sexual behaviors mentioned and the (hypo)manic symptoms evaluated with the MDQ are related to the entire lifetime. In addition, this is a transversal study with limitations due to its design; therefore it can not make solid conclusions about prognosis of HIV patients with AUD. Finally, it was limited to one geographical area and may not be generalized to all HIV patients.

According to Samet et al. [33], given the high prevalence of AUD among HIV-infected patients, as well as the worse outcomes related to alcohol consumption described in the literature, screening for AUD 
should be performed in all patients initiating HIV medical care. A recent meta-analysis which evaluated the efficacy of interventions on risk behaviors among people living with HIV did not find significant reduction of alcohol abuse related to these interventions [44]. In this sense, new strategies aiming at reducing alcohol abuse among HIVinfected patients with AUD need to be developed, in order to provide a better prognosis to these patients.

In conclusion, there is a highly significant prevalence of AUD among HIV-infected patients. AUD showed the following profile: young males, living alone, with lower education, higher rates of (hypo)manic symptoms and drug and sexual risk behaviors. A better understanding of AUD comorbidity and its implications on behavioral aspects of HIVpositive individuals may help in providing better long term outcomes of these patients.

\section{Acknowledgements}

This study was supported by DECIT/SCTIE/MS/CNPq/FUNCAP/SESA Award 09100225-7 PPSUS 002/2009.

\section{References}

1. Global HIVIAIDS response (2011) Epidemic update and health sector progress towards Universal Access, Progress Report.

2. Strathdee SA, Abramovitz D, Lozada R, Martinez G, Rangel MG, et al. (2013) Reductions in HIV/STI Incidence and Sharing of Injection Equipment among Female Sex Workers Who Inject Drugs: Results from a Randomized Controlled Trial. PLoS One 8: e65812.

3. Li HM, Peng RR, Li J, Yin YP, Wang B, et al. (2011) HIV incidence among men who have sex with men in China: a meta-analysis of published studies. PLoS One 6: e23431.

4. Moore RD (2011) Epidemiology of HIV infection in the United States: implications for linkage to care. Clin Infect Dis 52: S208-213.

5. Brazilian Ministry of Health (2012) Boletim Epidemiológico HIVIAIDS.

6. WHO (2011) Global status report on alcohol and health

7. Scott-Sheldon LA, Walstrom P, Carey KB, Johnson BT, Carey MP, et al. (2013) Alcohol Use and Sexual Risk Behaviors among Individuals Infected with HIV: A Systematic Review and Meta-Analysis 2012 to Early 2013. Curr HIVIAIDS Rep 10: 314-323.

8. Fisher JC, Bang H, Kapiga SH (2007) The association between HIV infection and alcohol use: a systematic review and meta-analysis of African studies. Sex Transm Dis 34: 856-863.

9. Sander PM, Cole SR, Stall RD, Jacobson LP, Eron JJ, et al. (2013) Joint effects of alcohol consumption and high-risk sexual behavior on HIV seroconversion among men who have sex with men. AIDS 27: 815-823.

10. Van Tieu H, Koblin BA (2009) HIV, alcohol, and noninjection drug use. Curr Opin HIV AIDS 4: 314-318.

11. Mijch A, Burgess P, Judd F, Grech P, Komiti A, et al. (2006) Increased health care utilization and increased antiretroviral use in HIV-infected individuals with mental health disorders. HIV Med 7: 205-212.

12. Ribeiro CM, Gurgel WS, Luna JR, Matos KJ, Souza FG (2013) Is bipolar disorder a risk factor for HIV infection? J Affect Disord 146: 66-70.

13. Prince JD, Walkup J, Akincigil A, Amin S, Crystal S (2012) Serious mental illness and risk of new HIVIAIDS diagnoses: an analysis of Medicaid beneficiaries in eight states. Psychiatr Serv 63: 1032-1038.

14. Meade CS, Bevilacqua LA, Key MD (2012) Bipolar disorder is associated with HIV transmission risk behavior among patients in treatment for HIV. AIDS Behav 16: 2267-2271.

15. Meade CS, Fitzmaurice GM, Sanchez AK, Griffin ML, McDonald LJ, et al. (2011) The relationship of manic episodes and drug abuse to sexual risk behavior in patients with co-occurring bipolar and substance use disorders: a 15-month prospective analysis. AIDS Behav 15: 1829-1833.

16. Svenaeus $F$ (2013) Diagnosing mental disorders and saving the normal: American Psychiatric Association, 2013. Diagnostic and statistical manual of mental disorders. (5thedn), American Psychiatric Publishing: Washington, DC, USA 991.
17. Nakimuli-Mpungu E, Musisi S, Mpungu SK, Katabira E (2006) Primary mania versus HIV-related secondary mania in Uganda. Am J Psychiatry 163: 13491354.

18. Brazilian Institute of Geography and Statistics (2010) Gross Domestic Product of Municipalities.

19. Saunders JB, Aasland OG, Babor TF, de la Fuente JR, Grant M (1993) Development of the Alcohol Use Disorders Identification Test (AUDIT): WHO Collaborative Project on Early Detection of Persons with Harmful Alcohol Consumption--II. Addiction 88: 791-804.

20. Amon J, Brown T, Hogle J, MacNeil J, Magnanl R, et al. (2000) Behavioral Surveillance Surveys: Guidelines for Repeated Behavioral Surveys in Populations at Risk of HIV. Family Health International, Arlington, USA.

21. Hirschfeld RM, Williams JB, Spitzer RL, Calabrese JR, Flynn L, et al. (2000) Development and validation of a screening instrument for bipolar spectrum disorder: the Mood Disorder Questionnaire. Am J Psychiatry 157: 1873-1875.

22. Grupo de Estudos em Transtornos Afetivos Affective Disorders Study Group de Sousa Gurgel W, Rebouças DB, Negreiros de Matos KJ, Carneiro AH, et al (2012) Brazilian Portuguese validation of Mood Disorder Questionnaire. Compr Psychiatry 53: 308-312.

23. Mehta SA, Silvera R, Bernstein K, Holzman RS, Aberg JA, et al. (2011) Awareness of post-exposure HIV prophylaxis in high-risk men who have sex with men in New York City. Sex Transm Infect 87: 344-348.

24. Hakre S, Arteaga G, Núñez AE, Bautista CT, Bolen A, et al. (2013) Prevalence of HIV and other sexually transmitted infections and factors associated with syphilis among female sex workers in Panama. Sex Transm Infect 89: 156-164.

25. Latkin C, Yang C, Tobin K, Roebuck G, Spikes P, et al. (2012) Social network predictors of disclosure of MSM behavior and HIV-positive serostatus among African American MSM in Baltimore, Maryland. AIDS Behav 16: 535-542.

26. Almeida-Filho N, Lessa I, Magalh es L, Araújo MJ, Aquino E, et al. (2004) Alcohol drinking patterns by gender, ethnicity, and social class in Bahia, Brazil. Rev Saude Publica 38: 45-54.

27. Mendoza-Sassi RA, Béria JU (2003) Prevalence of alcohol use disorders and associated factors: a population-based study using AUDIT in southern Brazil. Addiction 98: 799-804.

28. Michel L, Carrieri MP, Fugon L, Roux P, Aubin HJ, et al. (2010) Harmful alcoho consumption and patterns of substance use in HIV-infected patients receiving antiretrovirals (ANRS-EN12-VESPA Study): relevance for clinical management and intervention. AIDS Care 22: 1136-1145.

29. Chander G, Josephs J, Fleishman JA, Korthuis PT, Gaist P, et al. (2008) Alcohol use among HIV-infected persons in care: results of a multi-site survey. HIV Med 9: 196-202.

30. Bertholet N, Cheng DM, Samet JH, Quinn E, Saitz R (2010)Alcohol consumption patterns in HIV-infected adults with alcohol problems. Drug Alcohol Depend 112: $160-163$.

31. Herttua K, Martikainen P, Vahtera J, Kivimäki M (2011) Living alone and alcohol-related mortality: a population-based cohort study from Finland. PLoS Med 8: e1001094.

32. Galvan FH, Bing EG, Fleishman JA, London AS, Caetano R, et al. (2002) The prevalence of alcohol consumption and heavy drinking among people with HIV in the United States: results from the HIV Cost and Services Utilization Study. J Stud Alcohol 63: 179-186.

33. Samet JH, Cheng DM, Libman H, Nunes DP, Alperen JK, et al. (2007) Alcohol consumption and HIV disease progression. J Acquir Immune Defic Syndr 46: 194-199.

34. Hicks PL, Mulvey KP, Chander G, Fleishman JA, Josephs JS, et al. (2007) The impact of illicit drug use and substance abuse treatment on adherence to HAART. AIDS Care 19: 1134-1140.

35. Baum MK, Rafie C, Lai S, Sales S, Page B, et al. (2009) Crack-cocaine use accelerates HIV disease progression in a cohort of HIV-positive drug users. $J$ Acquir Immune Defic Syndr 50: 93-99.

36. Kalichman SC, Simbayi LC, Kaufman M, Cain D, Jooste S (2007) Alcohol use and sexual risks for HIVIAIDS in sub-Saharan Africa: systematic review of empirical findings. Prev Sci 8: 141-151.

37. Bloomfield K, Wicki M, Wilsnack S, Hughes T, Gmel G (2011) International differences in alcohol use according to sexual orientation. Subst Abus 32: 210-219. 
Citation: de Luna JRG, de Sousa Gurgel W, de Matos KJN, Barros EM, da Frota Ribeiro CM, et al. (2014) The Influence of Alcohol Use Disorders on Sex and Mood in an HIV-infected Population in the State of Ceará, Northeastern Brazil. J AIDS Clin Res 5: 285. doi:10.4172/2155-6113.1000285

38. Ludford KT, Vagenas P, Lama JR, Peinado J, Gonzales P, et al. (2013) Screening for drug and alcohol use disorders and their association with HIVrelated sexual risk behaviors among men who have sex with men in Peru. PLoS One 8: e69966.

39. Beaulieu S, Saury S, Sareen J, Tremblay J, Schütz CG, et al. (2012) The Canadian Network for Mood and Anxiety Treatments (CANMAT) task force recommendations for the management of patients with mood disorders and comorbid substance use disorders. Ann Clin Psychiatry 24: 38-55

40. Grant JD, Scherrer JF, Lynskey MT, Agrawal A, Duncan AE, et al. (2012) Associations of alcohol, nicotine, cannabis, and drug use/dependence with educational attainment: evidence from cotwin-control analyses. Alcohol Clin Exp Res 36: 1412-1420.
41. Ferreira LN, Bispo Júnior JP, Sales ZN, Casotti CA, Braga Junior AC (2013) [Prevalence and associated factors of alcohol abuse and alcohol addiction] Cien Saude Colet 18: 3409-3418.

42. Reisdorfer E, Büchele F, Pires RO, Boing AF (2012) Prevalence and associated factors with alcohol use disorders among adults: a population-based study in southern Brazil. Rev Bras Epidemiol 15: 582-594.

43. Pinsky I, El Jundi SA (2008) [Alcohol advertising and alcohol consumption among youngsters: review of the international literature]. Rev Bras Psiquiatr 30: $362-374$.

44. Wang N, Sun X, Yin L, Liu H, Ruan Y, et al. (2013) Meta-Analysis of Interventions for Reducing Number of Sexual Partners and Drug and Alcohol Abuse among People Living with HIVIAIDS. J AIDS Clin Res 4 